\title{
Design and Analysis of Automobile Composite Muffler Model
}

\author{
Dongwei Wang \\ Xiamen University Tan Kah Kee College, Fujian, China
}

\begin{abstract}
This paper introduced the theoretical design of automotive muffler. The muffler three-dimensional model was established using the computer, and convert the format of the three-dimensional model into STL, then by using the method of rapid prototyping, print out the muffler entities. By using the related theory, the noise attenuation quantity was calculated, and it provides reference for the muffler design and production.
\end{abstract}

Keywords-noise elimination; composite muffler; rapid prototyping manufacturing technology

\section{INTRODUCTION}

With the rapid development of China's economy, the number of motor vehicles has also increased dramatically, also aggravate rising emissions and noise pollution in the process of vehicle exhaust, causing environmental pollution more serious. The greenhouse effect becomes more and more prominent. In the city, exhaust pollution and noise pollution of automobile exhaust is more serious, resulting in a series of environmental pollution, and seriously affect people's quality of life and health. It is seriously endanger for the sustainable development of our country. In order to reduce the emission noise and reduce the exhaust emission, a muffler device with a silencer performance maybe installed on the exhaust system of the motor vehicle. The exhaust muffler is the most effective and simple way to reduce the noise of the engine.

Rapid prototyping is a method of forming parts based on the principle of separation and accumulation, which integrates computer technology, numerical control technology, laser processing technology and new material technology. The basic principle is: any 3D parts can be regarded as many twodimensional plane along a coordinate direction of superposition, so it can be discrete 3D model into a series of plane geometry information in CAD system, using adhesive, melting, polymerization or chemical reaction means exhaustive selective curing liquid (or bonded solid material), thus rapid accumulation to produce prototype parts required (or parts). The rapid prototyping technology in the realization method and manufacturing ideas to achieve a breakthrough, its biggest advantage is rapid design, modification and evaluation of products, but also can put the design into a prototype in a short period of time (with certain functions, samples) not only reduce the cost of product development, but also greatly shorten the product development cycle, so that enterprises in the first time to meet the needs of the market, improve the comprehensive competitiveness of enterprises, and can make 3D arbitrary complex, solve a lot of traditional design and manufacture of a hard problem.

\section{StRUCTURE Design OF A COMBINED MUfFLER}

The exhaust air system on the motor vehicle has totally installed noise-abatement equipment which possesses the function of noise elimination. These equipments are called noise deadener. This paper has built the model of automotive noise deadener by using the college equipment. The transformation of contrivable models was materialized under the skill of rapid prototyping, and the acoustical behavior was analyzed as well. The design and manufacture of noise deadener can mainly meet design requirements.

\section{A. Design Procedure}

The design of the entity processing manufacturing is the use of YINHUA's G1A, mainly used Model Wizard software to achieve control of the entity making procedure, so as to realize the three-dimensional entity model design. The main processes are: the establishment of the three-dimensional model, the conversion of the three-dimensional model format (STL format), the data loading, the determination of the working parameters and the entity processing. After all the equipment is ready, it is necessary to connect the system software and the machine to realize the control of the machine by software.

\section{B. Molding Production by RP}

Rapid Prototyping is an emerging technology of advanced manufacturing at $90^{\text {th }}$, which is a key common technology of new product development services for manufacturing enterprises [1]. It is also called the entity free manufacture, the tabletop processing or folds the level processing technology. It based on the manufacture principle of separation stack of increases the material, which is different from the conventional go timber material processing [2]. For the cascade accumulation manufacture method to complete any complex spare part or the manufacture of the entity, it is the simple and direct fabrication technology for processing any complex parts in practice. The result can be used to promote manufacturing enterprise product's innovation, shorten the development cycle of new products designed. It has played a positive role in promoting automobile's enterprises development and market competitiveness of the products [3].

Conversion of 3D model format: because the equipment can only identify the STL format type FDM data file, so we must model data will be used before Solidworks software SLDPRT format converted into the required format of STL data file, then it can be made compatible with the Model Wizard software. 
Data loading: data loading is the conversion of the STL file into the control software Model Wizard, for the next step to change the parameters and determine the preparation. However, before loading the file, you need to manually connect the system software and the machine to achieve the initial connection and initialization.

According to the structural characteristics of the 3D solid model, the machining direction is selected, and the plane of the same height is cut in the height direction of the model. The thickness of the plane generally is $0.05 \mathrm{~mm} \sim 0.5 \mathrm{~mm}$, which depends mainly on the manufacturing accuracy of the machine.

Through the software under the control of the computer, according to the profile section of nozzle molding equipment on the work table of a layer material accumulation, and then each layer, the final product prototype should be got.

After the process of grinding, polishing, coating, scaling, supporting structure, the model is processed as shown in the following Fig. I and Fig. II.

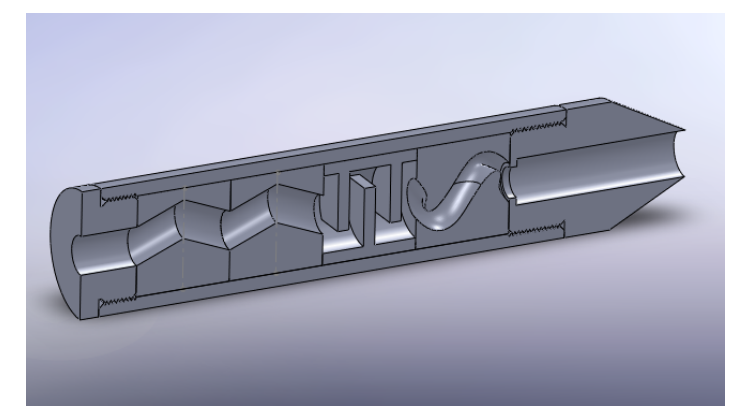

FIGURE I. SEMI SECTIONAL VIEW OF 3D ASSEMBLY DRAWING OF MUFFLER

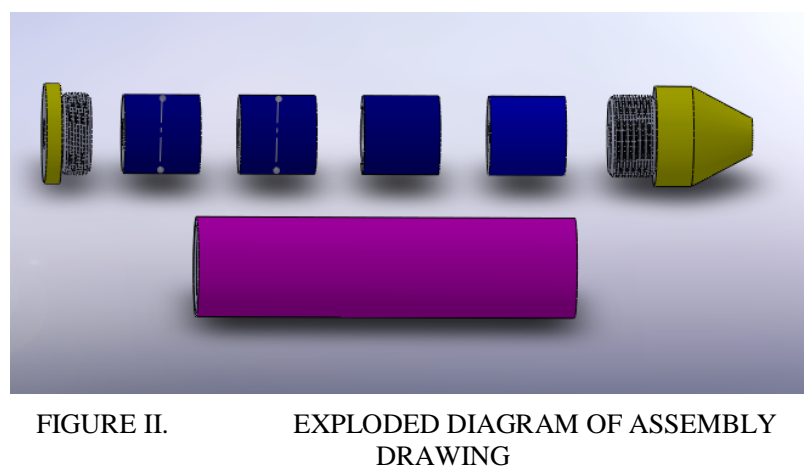

\section{CALCULATION OF MUfFLER'S THEORETICAL NOISE}

As the design uses a resistance muffler, so the muffler theoretical calculation should be used to calculate the noise reduction, the calculation process is as follows:

\section{A. High Frequency Failure Frequency [4]}

If the acoustic frequency is higher, the direction of propagation is stronger. For a given flow channel, when the frequency is higher than a certain value, because the direction of acoustic waves in the muffler is very strong and the formation of "beam" shape propagation, little or no contact with sound-absorbing material attached on the pipe wall, noise reduction of the muffler maybe significantly decreased. The frequency of occurrence of this decrease is the "high frequency failure frequency":

$$
f_{n}=1.85 \frac{C}{D}
$$

In the formula (4-11), C is the speed of sound (m/s); D is the muffler channel equivalent diameter $(\mathrm{m})$; the average value of the pipe length is taken for a rectangular shape; the pipe diameter is taken as the square root of the rest area.

When the frequency is higher than the high-frequency failure frequency, each doubling of the frequency, the attenuation will be more than $1 / 3$ of the high frequency of noise reduction. The amount of noise at a frequency above the failure frequency can be calculated using the following expressions:

$$
\triangle_{N R}=\left(1-\frac{N}{3}\right) L_{N R}
$$

In the formula (4-12), $\triangle L_{N R}$ is the noise reduction of high frequency attenuation at sometime for failure frequency; $L_{N R}$ is noise reduction for high failure frequency; $\mathrm{N}$ is the multiple coefficient high-frequency failure frequency.

Because the sound velocity of the motor vehicle exhaust system is $340 \mathrm{~m} / \mathrm{s}$, the high-frequency failure frequency of the muffler can be calculated by the formula (1):

$$
f_{n}=1.85 \frac{C}{D}=1.85 \times 340 \div 0.01=62900 H z
$$

\section{B. Attenuation of Acoustic Waves in Resistive Ducts}

When the muffler is folded plate deformation type, acoustic muffler improved, so calculating the amount of noise elimination of the one-dimensional is based on A.N. Belov theory:

$$
L_{N R}=2 \varphi\left(a_{0}\right) \frac{l}{a}
$$

In the formula (3), $l$ is the effective part length of the muffler; $\alpha$ the width of the flow channel; $\varphi\left(a_{0}\right)$ known as the coefficient of noise, which indicates that the propagation distance is equal to half the width of the pipeline. The conversion relation between the attenuation coefficient and the sound absorption coefficient of the material is shown in table I.

TABLE I. CONVERSION COEFFICIENT AND SOUND ABSORPTION COEFFICIENT

\begin{tabular}{|l|l|l|l|l|l|l|l|l|}
\hline$a_{0}$ & 0.05 & 0.10 & 0.15 & 0.20 & 0.30 & 0.35 & 0.40 & 0.45 \\
\hline$\varphi\left(a_{0}\right)$ & 0.05 & 0.11 & 0.17 & 0.24 & 0.31 & 0.39 & 0.47 & 0.55 \\
\hline$a_{0}$ & 0.50 & 0.55 & 0.6 & 0.7 & 0.8 & 0.9 & 1.0 & \\
\hline$\varphi\left(a_{0}\right)$ & 0.64 & 0.75 & 0.85 & 1.1 & 1.3 & 1.4 & 1.5 & \\
\hline
\end{tabular}

By the formula (1) and table 1 we calculated amount of noise elimination of the folded plate type muffler: 


$$
\begin{aligned}
L_{N R 1} & =2 \varphi\left(a_{0}\right) \frac{l}{a}=2 \times \varphi\left(a_{0}\right) \times \frac{0.025}{0.01} \\
L_{N R 2} & =2 \varphi\left(a_{0}\right) \frac{l}{a}=2 \times \varphi\left(a_{0}\right) \times \frac{0.025}{0.01}
\end{aligned}
$$

Due to the use of the design of the muffler is made of plastic material, it is available in high frequency sound absorption coefficient of the failure frequency, because when the frequency is above $8000 \mathrm{~Hz}$, the magnitude is very small, can be ignored, just get to $8000 \mathrm{~Hz}$, as shown in table II.

TABLE II. $\quad a_{0} L_{N R 1} \& L_{N R 2}$ OF THE CORRESPONDING FREQUENCY

\begin{tabular}{|l|l|l|l|l|l|l|l|}
\hline $\mathrm{F} / \mathrm{Hz}$ & 125 & 250 & 500 & 1000 & 2000 & 4000 & 8000 \\
\hline$a_{0}$ & 0.19 & 0.64 & 0.73 & 0.62 & 0.20 & 0.14 & 0.10 \\
\hline $2 L_{N R 1}$ & 2.20 & 9.80 & 11.70 & 9.00 & 2.40 & 1.60 & 1.10 \\
\hline$L_{N R 2}$ & 1.10 & 4.90 & 5.85 & 4.50 & 1.20 & 0.80 & 0.55 \\
\hline
\end{tabular}

The performance of the labyrinth muffler is related to the size of the room, the cross section of the channel, the sound absorbing material and its area. Its amount of noise elimination can be calculated as flow:

$$
L_{N R 3}=10 \lg \frac{\alpha S_{1}}{(1-\alpha) S_{2}}
$$

In the formula (4), $\alpha$ is the sound absorption coefficient of the lining sound-absorbing material; $S_{1}$ is used as the surface area of the inner lining sound-absorbing material; $S_{2}$ is the cross-sectional area of entrance and exit. For the muffler $S_{1}=1.29 \times 10^{-3} \mathrm{~m}^{2}, \quad S_{2}=3.14 \times 10^{-4} \mathrm{~m}^{2}$

The Total attenuation of the muffler:

$$
L_{N R}=2 L_{N R 1+} L_{N R 2+} L_{N R 3}
$$

\section{CONCLUSION}

The total attenuation of the muffler in the operating frequency below the high frequency failure frequency is shown in table III and Fig. III.:

\section{TABLE III. CORRESPONDING ATTENUATION TO EACH FREQUENCY BELOW THE HIGH-FREQUENCY FAILURE} FREQUENCY

\begin{tabular}{|l|l|l|l|l|l|l|l|}
\hline $\mathrm{f} / \mathrm{Hz}$ & 125 & 250 & 500 & 1000 & 2000 & 4000 & 8000 \\
\hline$a_{0}$ & 0.19 & 0.64 & 0.73 & 0.62 & 0.20 & 0.14 & 0.10 \\
\hline$L_{\mathbb{R}}$ & 3.30 & 15.34 & 28.01 & 21.76 & 3.72 & 2.4 & 1.65 \\
\hline
\end{tabular}
in the

According to the model, the results of calculation are given Acce

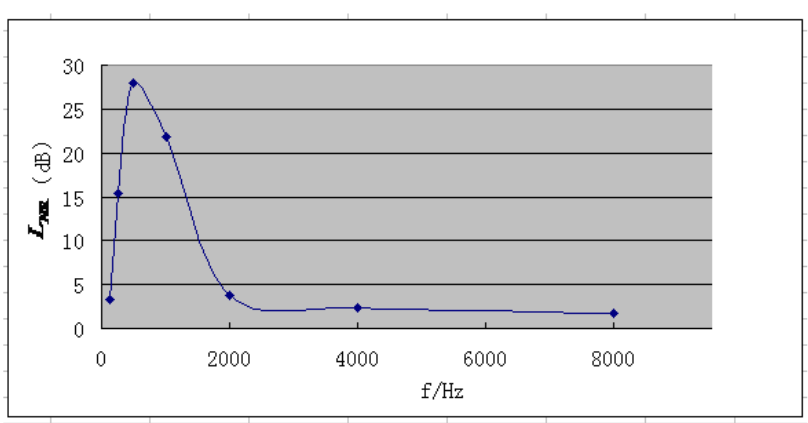

FIGURE III. THE RELATIONSHIP CURVE EACH FREQUENCY F BELOW HIGH FREQUENCY FAILURE FREQUENCY

From Fig. III we can see that in the effective working frequency (below high failure frequency), when the frequency is about $500 \mathrm{~Hz}$, the best silencing effect of the muffler, is about $28 \mathrm{~dB}$, but because the car in the normal condition, the 4 cylinder 6000rpm engine frequency is $200 \mathrm{~Hz}$, the attenuation at this time the muffler is about $10 \mathrm{~dB}$; four cylinder 3000rpm engine at the frequency of $100 \mathrm{~Hz}$, it can be inferred that the muffling volume is about $3 \mathrm{~dB}$; if in order to improve the attenuation volume, according to formula (4-13) shows that the increase of the effective part of muffler length $\mathrm{L}$, reduce the airflow channel width and using the higher absorption coefficient material can effectively improve the muffler performance.

The design of the muffler we made by using acoustic principle to achieve the true meaning of the weakening of the noise. It is used to reduce the noise of the muffler in series, and the maximum amount of noise can reach $28 \mathrm{~dB}$. Because of the experimental equipment and some constraints, noise elimination may not be calculated accurately. If the conditions permit, we can do something to achieve a better silencing effect, so that the muffler can be effective in series four anechoic length resistive components of moderate growth, or by the use of the sound absorption coefficient of better material, and moreover channel width decreases to a certain extent by changing the dimensions of muffler. Due to the design time, equipment, conditions, economic and personal ability to limit, this study can only achieve the effect, needs to be extended for further study.

\section{REFERENCES}

[1] Liu Weijun. Rapid prototyping technology and its application [M]. Publishing House: Mechanical Industry Press, 2005-1.

[2] Fan Chunhua. Zhao Jianfeng.. rapid prototyping technology and its application [M]. Publishing House: Publishing House of electronics industry, 2009-3.

[3] An Ping. Material forming technology [M]. Publishing House: Science Press, 2008

[4] Liu Huiling. Environmental noise control [M]. Publishing House: Harbin Institute of Technology press, 2002-10s

[5] [Zhou Xinxiang. Noise control technology and its new progress [M]. Publishing House: Metallurgical Industry Press, 2007-7.

[6] Wei Zhiyong. Industrial noise and vibration control technology [M]. Publishing House: China labour and Social Security Publishing House, 2010-10.

[7] Wu Zongze, Luo Shengguo. Mechanical design curriculum design manual [M]. Publishing: Higher Education Press, 1999 
[8] Yuan Changming. Cloud. Chinese dietary composition. Noise and vibration control technology of [M]. Publishing: Metallurgical Industry Press, 2007-7.

[9] Sheng Meiping Wang Minqing. Sun Jincai. Noise and vibration control technology base (Second Edition) [M]. published: Science Press, 200712.

[10] Ying Huaijiao. Vibration and noise of modern technology [M]. Publishing: Aviation Industry Press, 2005-10.. 